http://dx.doi.org/10.21707/gs.v11.n02a09

\title{
A Tradicionalidade do AGRICULTOR FAMILIAR DO CERRADO PIAUIENSE
}

\section{Antonio Joaquim da Silva ${ }^{1 *}$, Maria do Socorro Lira Monteiro ${ }^{2}$, Eriosvaldo Lima Barbosa ${ }^{3}$}

\author{
${ }^{1}$ Docente do Instituto Federal de Educação, Ciência e Tecnologia do Piauí \\ ${ }^{2}$ Docente do Departamento de Ciências Econômicas, Centro de Ciências Humanas e Letras, Universidade Federal do Piauí \\ ${ }^{3}$ Docente do Departamento de Planejamento e Política Agrária, Centro de Ciências Agrárias, Universidade Federal do Piaui \\ *Autorpara correspondência: antoniojoaquim@ifpi.edu.br
}

Recebido em 19 de fevereiro de 2016. Aceito em 13 de maio de 2017. Publicado em 29 de julho de 2017.

Resumo - O desenvolvimento do agronegócio no cerrado piauiense é um fenômeno recente da história agrário/ agrícola do Brasil. Esse movimento de expansão da fronteira agropecuária tem repercutido em intensas alterações nas paisagens e nos modos de vida rurais, os quais incluem saberes, práticas e conhecimentos baseados nas estratégias econômicas, sociais, culturais e ambientais de sobrevivência das populações das localidades. Nessa perspectiva, ressaltase que este artigo pretende analisar a situação dos modos de vida dos agricultores familiares do cerrado piauiense, na medida em que este ator social se insere no mundo globalizado conservando limites que permitem a manutenção de sua etnicidade, por meio da tradição e cultura. O estudo elegeu Uruçú, município localizado no bioma Cerrado e que se destaca por ser pioneiro em abrigar empresas de agronegócios no Piauí e por oferecer a infraestrutura necessária para o agronegócio modernizar as áreas de chapadas, visando a produção de exportáveis. Esta pesquisa qualiquantitativa tem natureza descritiva/explicativa, embasada no método etnogeográfico, o qual foi subsidiado por observações sistemáticas, formulários e entrevistas semiestruturados com 254 agricultores familiares, com vistas a conhecer saberes, objetos e práticas de trabalho agrícola, códigos de interconhecimento, relações culturais e identidade. Concluiu-se que os modos de vida dos agricultores familiares denotavam uma ciência do equilíbrio carregada de valores simbólicos e marcada por um patrimônio de saberes, conhecimentos, experiências e técnicas tradicionais que se ajustava precariamente às tecnologias modernas. E que as relações de reciprocidade não foram diluídas com a chegada do agronegócio, tampouco a produção agropecuária desprezava as linguagens de matriz camponesa.

Palavras-chave: Agronegócio; Cerrado; Modos de Vida; Tradiçäo.

\section{The traditionality of family farmers in the Cerrado of Piauí state, Brazil}

ABstract - The agribusiness development in the Cerrado of Piauí Stateis a recent phenomenon in the agrarian/agricultural history of Brazil. This movement of expansion of the agricultural frontier has had repercussions on intense changes in landscapes and rural ways of life, which include wisdom, practices and knowledge based on economic, social, cultural and environmental strategies for the survival of local population. In this perspective, this study intends to analyze the ways of life conditions of the family farmers in the Cerrado of Piauí State, as these social actors are inserted in the globalized world keeping limits to allow the maintenance of their ethnicity by the tradition and culture. The study was carried out in the municipality of Uruçuí, located in the Cerrado biome.This municipality stands out for being a pioneer in housing agribusiness companies in Piauí State and for supplying the necessary infrastructure for agribusiness to modernize the plateau areas, aiming at the production of exportable products. This qualitative and quantitative research has a descriptive/ explanatory nature, based on the ethnogeographic method, which was supported by systematic observations, forms and semi-structured interviews with 254 family farmers, aimed to know about their knowledge, objects and agricultural practices, codes of inter-knowledge, cultural relationships and identity. It was concluded that the ways of life of family farmers were a balancing science with lots of symbolic values and marked by a heritage of knowledge, wisdom, experiences and 
traditional techniques that precariously adjusted to the modern technologies, and that neither relationships of reciprocity were diluted with the arrival of the agribusiness, nor the farming production disregarded the languages of peasant matrix.

KeYwords: Agribusiness; CERRADO; W AYS OF LIFE; TRADITION.

\section{La tradicionalidad del agricultor familiar del cerrado del estado de Piauí, Brasil}

REsumen - El desarrollo del agronegocio en el cerrado piauiense es un fenómeno reciente de la historia agraria/agrícola de Brasil. Ese movimiento de expansión de la frontera agropecuaria ha repercutido en intensas alteraciones en los paisajes y en los modos de vida rurales, los cuales incluyen saberes, prácticas y conocimientos basados en las estrategias económicas, sociales, culturales y ambientales de sobrevivencia de las poblaciones locales. En esta perspectiva, este estudio pretende analizar la situación de los modos de vida de los agricultores familiares del cerrado piauiense, a medida que estos actores sociales se insertan en el mundo globalizado conservando límites que permiten el mantenimiento de su etnicidad, por medio de la tradición y cultura. El estudio se condujo en Uruçuí, municipio ubicado en el Cerrado y que se destaca por ser el pionero en abrigar empresas de agronegocios en Piauí y por ofrecer la infraestructura necesaria para que el agronegocio pudiera modernizar las áreas de chapadas, visando la producción de exportables. Esta investigación cuali-cuantitativa es de carácter descriptivo/explicativo, basada en el método etnogeográfico, el cual consistióen observaciones sistemáticas, formularios y encuestas semiestructuradas con 254 agricultores familiares, buscando conocersus saberes, objetos y prácticas de trabajo agrícola, códigos de interconocimiento, relaciones culturales e identidad. Se concluyó que los modos de vida de los agricultores familiares denotan una ciencia del equilibrio cargada de valores simbólicos y marcada por un patrimonio de saberes, conocimientos, experiencias y técnicas tradicionales que se ajustan precariamente a las tecnologías modernas, y que las relaciones de reciprocidad no fueron diluidas con la llegada del agronegocio y que tampoco la producción agropecuaria desprecia los lenguajes de matriz campesina.

Palabras clave: Agronegocio; Cerrado; Modos de Vida; Tradición.

\section{INTRODUÇÃo}

Recentemente, a consolidação do agronegócio no cerrado brasileiro, por meio da cadeia grãos/carnes, tem incrementado uma modernização tecnológica que impõe uma padronização produtiva que insere o território numa hierarquia de fluxos agenciados globalmente (Haesbaert, 2006; Moraes, 2009; Silva, Monteiro, Barbosa, 2016a), resultando em alterações na paisagem, nas relações sociais do trabalho, na propriedade e uso da terra e nos projetos de vida da população local (Silva, Monteiro, Silva, 2015).

Em virtude desse cenário, Silva, Monteiro e Silva (2015), Silva, Monteiro e Barbosa (2015) e Silva (2016) advertem que o avanço sistemático do agronegócio no cerrado piauiense, tem intensificado as inovações tecnológicas, conferindo à fronteira elevada produtividade agrícola, a tendência de aumento dos lucros, o acirramento dos conflitos sociais (em função da predominância de concentração fundiária) e a degradação dos recursos ambientais, o que tem interferido nos modos de vida do agricultor familiar.

Ressalta-se que nesta investigação, a compreensão de agricultura familiar sustenta-se nas interpretações teóricas e metodológicas que enfatizam, fundamentalmente, a persistência de contextos históricos, em especial, da tradicionalidade camponesa, com vistas a continuidade social do agricultor familiar vis à vis ao mundo globalizado, como a análise de Silva (2016), de que a agricultura familiar além de validar-se num conceito técnico/operacional criado por agentes governamentais, consiste, sobretudo, a definir-se numa instituição social calcada nas virtudes da sociedade camponesa, haja vista que a tradicionalidade legitima-se como uma singularidade que não se esgota 
ante as contradições espaço/tempo. Essa tradicionalidade, para Ribeiro (2012), confere uma realidade concreta em que as condições históricas, sociais e culturais possuem prestígio na concepção de virtudes de um grupo.

Logo, reconhece-se a importância da tradição nos modos de vida do agricultor familiar, por envolver passado e presente e se vincular ao futuro. Ademais, de acordo com Giddens (1991), a tradição se apresenta como uma orientação para o passado, de tal modo que as ordens sociais pré-modernas tem uma ampla influência ou, mais precisamente, são projetadas para preservar a história e a memória coletiva para o presente. Então, a tradição denota, em certa medida, o controle do tempo.

Por outro lado, compreende-se também, em conformidade com Giddens (1991), que a globalização, que referencia e influencia aspectos da reprodução do capital, estabelece a separação espaço/tempo, propiciando o desenvolvimento de mecanismos de encaixe (continuidade) e desencaixe (descontinuidade) entre os conteúdos tradicionais variados e os novos estilos de vida da sociedade. Dessa forma, nas condições contemporâneas tais mecanismos executam os movimentos das práticas dos agricultores familiares, governando aspectos da vida cotidiana e reestruturando as ordens sociais tradicionais aos imperativos da modernização e mercantilização do campo.

Partindo desse pressuposto, registra-se, segundo Silva, Monteiro e Barbosa (2016b), que os modos de vida expressam as estratégias econômicas, sociais, culturais e ambientais de resistência do agricultor familiar num rural em constante mudança. Ou seja, compreendem os modos de vida como a forma por excelência de representação e organização do trabalho e da vida familiar.

A análise de Silva, Monteiro e Barbosa (2016b) faz analogia às ideias de Scott (2002), que concebe a tradicionalidade como o resultado da resistência da ordem moral que orienta a vida comunitária. Seguramente que essa resistência da tradição indica um certo encapsulamento para não se permitir subsumir pelo outro, mesmo que com este mantenha trocas de outras dimensões.

Já Lobo (1992), explica que os modos de vida propõem a indução de um fio condutor para o exame das redes do tecido social (sociabilidades), das subjetividades do campo simbólico e da moral prática, que comandam os comportamentos humanos. Outrossim, enfatiza que os estudos sobre os modos de vida remetem à análise das situações de vida, das estratégias de sobrevivência e da autonomia de sujeitos sociais heterogêneos. Sob a ótica de Ribeiro (2012), campo simbólico denota um sistema de cultura ou de significações no qual determinado grupo (e nele seus indivíduos) compreende e organiza seu mundo. Por sua vez, Deleuze (2001) esclarece que a moral é um sentimento produzido pela natureza humana, ou seja, é um senso do dever no qual as ações de cada um se relacionam com as dos outros. Deleuze (2001) respalda ainda que no domínio da moral, as regras gerais ordenam a consciência de aprovar e reprovar um caráter ou uma virtude particular.

De fato, não obstante a importância da tradicionalidade, pontua-se que os modos de vida representam formas tradicionais, padrões de ensinamentos/aprendizagens e sistemas de linguagens assentados nas práticas sociais e no habitus ou hábitos, os quais criam e recriam saberes e fazeres calcados na vivência e interação com o território, capitaneados por um saber-fazer que induz transformar possibilidades em recursos (Bourdieu, 1988, 1991; Moraes, 2009; Silva, Monteiro, Barbosa, 2016b).

Nessa via de pensamento, Fernandes (1992) evidencia a família como conditio sine qua non para o debate sobre os modos de vida, na medida em que o trabalho familiar se inscreve como categoria fundadora, ordenadora, sistematizadora e instauradora de sentidos e projetos úteis de existência social.

Essa vertente também é aceita por Chayanov (1974), por relatar que na exploração da unidade de produção 
familiar o agricultor utiliza, dentro de suas possibilidades, todas as oportunidades relacionadas às peculiaridades ambientais, históricas e os objetivos do mercado ao qual está inserido. Tal contextura ratifica que os modos de vida se centram no balanço trabalho/consumo necessário para satisfazer, qualitativamente, o bem-estar familiar.

Todavia, Muñoz (2003) sublinha que os modos de vida configuram a percepção do território como lugar de pertencimento, enraizamento, produção e manifestação de saberes individuais e comuns, baseados no respeito, nas narrativas da memória ancestral e nas diversas habilidades identitárias estabelecidas pela convivência. Sendo assim, define-os como um saber que está estreitamente ligado com as ações e práticas comunitárias.

Diante desse panorama, concorda-se com a assertiva de Escobar (2000), de que os modos de vida vinculamse ao território, à cultura e ao lugar, alicerçados na experiência, limites, conexões e conhecimento sobre um local, onde as identidades, práticas e relações socioespaciais são construídas ao longo do tempo.

A propósito, Ribeiro (2012) realça que tais práticas supõem um contexto organizado, estruturado, complexo e coerente das virtudes exercidas pela atividade humana que, em parte, recebem sua definição. Essa uniformidade se fundamenta na realização de bens, externos e internos, que são socialmente estabelecidos como padrões de eficiência e excelência, e determinantes para o reconhecimento e identificação de tipos específicos de vida. Dessa forma, ilustra que os bens externos são aqueles associados às circunstâncias, por exemplo: poder, riqueza e prestígio social. Já os bens internos envolvem obediência às normas fixadas historicamente.

Destaca-se que o argumento de Ribeiro (2012) se calca, preponderantemente, nas reflexões de MacIntyre (1984), sobre a concepção de virtudes, entendidas como qualidades que capacitam e valorizam as tradições. Logo, constata que as virtudes instituem e tornam onipresente e onisciente o caráter das relações entre homens e mulheres no interior das práticas.

Com base nas argumentações retrocitadas, entende-se porque Pereira (2004) adverte que a racionalidade da reprodução familiar exige a reafirmação dos valores de preservação da cultura local e extrapola as funções econômicas. Nesse enfoque, faz-se necessário atentar para os modos de vida dos agricultores familiares, materializados no existir cotidiano, na transmissão transgeracional e socializado num certo território. Essa transmissão transgeracional, segundo Feldman e Laland (1996), compreende as características comportamentais e de personalidade fixadas pela aprendizagem e cultura, que inclui as crenças, concepções e doutrinas, que são transferidas de uma geração para a seguinte. Portanto, destaca-se o imperativo de uma abordagem que tem antecedentes na tradição cultural camponesa, já que para Wanderley (2003), o agricultor familiar é um ator social que se ajusta à modernização do campo e às mudanças nos padrões de vida da sociedade, mas que não perde a raiz camponesa.

Alicerçado nessa contextura, verifica-se, em consonância com Muñoz (2003), que o cotidiano produz saberes, seja porque denota a aprovação isolada de técnicas e conhecimentos, seja porque envolve sujeitos e recursos naturais. Infere-se que essa assertiva vai ao encontro da opinião de Escobar (2000), de que os modos de vida designam o vínculo social com o lugar, diametralmente referenciado nos símbolos, rituais, significados, conhecimentos e práticas produtivas locais, baseados nos processos históricos, ecológicos, linguísticos e culturais.

Sepúlveda et al. (2003) também reconhecem a importância dos modos de vida na combinação de ativos (recursos materiais e sociais) e atividades (agricultura, artesanato, extrativismo, pesca, caça, etc.) para a configuração de um gênero de sobrevivência viável para as famílias rurais.

Outra caracterização verossímil de modo de vida rural é tematizada por Jiménez (2009), ao defender que os modos de vida distinguem a identidade tradicional do mundo rural, na medida em que consistem de sistemas 
de significados, expressões, normas e símbolos característicos, que se apoiam na cultura e na história de vida da população.

Em vista disso, confere-se que a economia camponesa ao mesmo tempo em que funciona essencialmente para responder às exigências familiares, atende as necessidades da coletividade local. Nesse enfoque, salienta-se a interpretação de Mendras (1978), de que o éthos do camponês se reproduz nos modos de vida, por situar num mesmo sistema de valores os códigos de comportamentos e as competências técnicas nos quais seriam comuns a todos, mas diferentes de sociedade para sociedade. Dessa forma, conclui que o éthos revela a harmonia, o estilo moral, o caráter ético e a qualidade de vida de uma sociedade.

Nessa direção, inclui-se o raciocínio de Moraes (2009), por qualificar os modos de vida como uma estrutura que organiza o sistema de cultivo agrícola, cujo resultado depende da interligação entre os arranjos técnicos e a natureza sociocultural. E por asseverar que os camponeses se relacionam com o ecossistema através de uma complexa classificação das paisagens e dos diferentes tipos de terrenos existentes, designando características relativas ao clima, ao solo e a vegetação.

Em linhas gerais, registra-se que essa realidade espelha os modos de vida das populações originárias dos cerrados, uma vez que para Rigonato (2014), nesses ambientes o conhecimento popular sobre a biodiversidade, especialmente, das fitofisionomias e paisagens, denota um valor sociocultural e socioeconômico inexorável para a sobrevivência do agricultor familiar, devido comportar o saber ecológico, mormente, personificado na utilidade de espécies nativas (manifestado nas práticas de coleta de frutos, folhas, raízes e cascas, além da madeira para queimar, construir, cercar e comercializar) e faunísticas (os ritos de caça ainda são influenciados pelas crenças e pela lua), nas peculiaridades históricas e nas particularidades geográficas reveladoras de inter-relações entre técnicas, cultura e identidades.

Diante do exposto, questiona-se como são os modos de vida do agricultor familiar do cerrado piauiense? Como a tradicionalidade camponesa tem resistido à ocupação e modernização empresarial do cerrado piauiense? E quais os horizontes de continuidade da tradicionalidade ante a territorialização capitalista do cerrado piauiense? Tais perguntas requerem perceber o rural como espaço de vida e trabalho, onde se busca, segundo Escobar (2014), recuperar o sentido da vida, com isso, as cosmovisões e práticas das comunidades rurais contribuem para a construção de um modelo de desenvolvimento alternativo, posto as externalidades negativas resultantes dos projetos expansionistas de desenvolvimento dominante.

Salienta-se, em conformidade com Alves (2015), que no léxico das Ciências Sociais, a categoria comunidade rural faz referência à propriedade coletiva dos recursos ambientais, combinada com a gestão e utilização privada. Conforme Escobar (2014), na comunidade o poder não está nas mãos de um indivíduo ou grupo específico, mas na coletividade. Dessa forma, compreende comunidade como uma entidade profundamente histórica, heterogênea e marcada por relações de poder.

Nesta investigação, a concepção de comunidade se embasa na análise de Tönnies (1995), que a qualifica como uma forma de organização social personificada espacialmente por laços pessoais e afetivos, por homogeneização no modo de agir e pensar e por vínculos de vizinhança compartilhados por meio de hábitos, costumes e tradições, cujas relações interpessoais são coesas e diretas.

Após tais considerações, sublinha-se que este artigo pretende analisar, por meio da variável cultural, os modos de vida de agricultores familiares do município de Uruçuí/PI, ante a ocupação capitalista do cerrado. Nesse município, Moraes (2003) evidencia que os agricultores familiares orientam os modos de vida a partir das 
condições proporcionadas pela natureza e por um intercâmbio sociocultural marcado pela tradição camponesa, que se perpetuaram ao longo do tempo e, que por sua vez, comandam as práticas produtivas e os diversos usos do cerrado. Nessas circunstâncias, afirma que os modos de vida em Uruçuí valorizam o lugar, enquanto espaço de vida e de trabalho.

Inclusive para Woortmann (2009), essa tradicionalidade camponesa se apresenta, nitidamente e exclusivamente, por meio de práticas agrícolas, onde o trabalho desprendido resulta num conhecimento complexo e relativo para com a terra. Além disso, encerra que o camponês demonstra respeito à natureza e às leis divinas.

A escolha de Uruçuí justifica-se em razão da agricultura familiar anteceder o agronegócio no Piauí, pois de acordo com Lopes (2008), o cerrado piauiense antes da chegada do agronegócio apresentava poucos núcleos urbanos, baixa densidade demográfica rural, isolamento das comunidades, sobretudo nos fundos de vales, e presença de grandes propriedades criadoras de gado. Além disso, Uruçuí se destaca por ser pioneiro em receber o agronegócio no cerrado piauiense, disponibilizar a infraestrutura para a instalação de empreendimentos e liderar o ranking de municípios com melhor PIB per capita do Estado, desempenho decorrente do Valor Adicionado (VA) da produção agropecuária (CEPRO, 2015).

Nesse sentido, reconhece-se a originalidade da temática, devido apresentar um conteúdo crítico sobre a complexidade dos processos causados pelo agronegócio no cerrado piauiense, na medida em que concretiza um arcabouço teórico para as discussões sobre as mudanças nos padrões tradicionais de produção e nas relações de vida da agricultura familiar. Como também, desperta para um reexame sobre as lógicas de resistência e reprodução do agricultor familiar frente à condição marginal que ocupa nas políticas públicas, particularmente, no Brasil. Desse modo, as reflexões a respeito do problema referendado foram dialogadas interdisciplinarmente com campos de saberes afins com o tema, como as Ciências Ambientais.

Sendo assim, este artigo estrutura-se em quatro seções, além desta introdução. A próxima seção apresenta a metodologia utilizada na investigação. A terceira seção trata dos resultados e discussões da pesquisa; e a quarta seção socializa as considerações finais do estudo.

\section{MATERial e mÉtodos}

Área de estudo

Andrade (1979, p.43) comenta que a população originária das terras ao sul do Piauí, como em Uruçuí, desenvolvia uma economia amonetária, pois utilizava, dentro de suas possibilidades, os recursos necessários para a subsistência do grupo doméstico, cultivando a terra, caçando animais silvestres, explorando a flora e a madeira, criando o gado e empregando o couro para os mais diversos misteres, sobretudo, para "confecção de selas e arreios para seus cavalos, roupas de trabalho, portas de casa, leito, bolsa para transporte de alimentos (o mocó) e recipiente para transportar água".

Consoante IBGE (2015), historicamente a formação de Uruçuí data de 23 de junho de 1902, por meio da Lei Estadual no 290, que elevou à categoria de distrito o povoado Nova Vila, o qual pertencia ao município de Bertolínia. Constata que a instalação da sede municipal ocorreu em 27 de setembro daquele ano, e que o motivo para a denominação relacionou-se aos fatores ambientais, haja vista que as terras ocupadas localizam-se no vale 
do rio Uruçuí Preto, que deságua no rio Parnaíba.

Uruçuí localiza-se no bioma Cerrado, possui área territorial de $8.452,025 \mathrm{~km}^{2}$, com sede situando-se nas coordenadas geográficas $07^{\circ} 13^{\prime} 46^{\prime \prime}$, latitude Sul e, 44³3’22”, longitude Oeste, e apresenta como limites geopolíticos, ao Norte, o estado do Maranhão e o município piauiense de Antônio Almeida, ao Sul, Alvorada do Gurgueia e Palmeira do Piauí, ao Leste, Sebastião Leal, Landri Sales e Manoel Emídio e, a Oeste, Baixa Grande do Ribeiro, Ribeiro Gonçalves e o estado do Maranhão. Em âmbito regional, o município compõe o Alto Parnaíba Piauiense, Microrregião constituinte da Mesorregião Sudoeste Piauiense (Figura 1). Conforme o IBGE (2010), neste ano, Uruçuí contava com um Índice de Desenvolvimento Humano Municipal (IDHM) de 0,631, e com uma população de 20.149 habitantes, cuja distribuição espacial distinguia-se em 15.506 e 4.643 habitantes nas zonas urbana e rural, respectivamente.

Figura 1 - Mapa de localização espacial de Uruçuí/PI

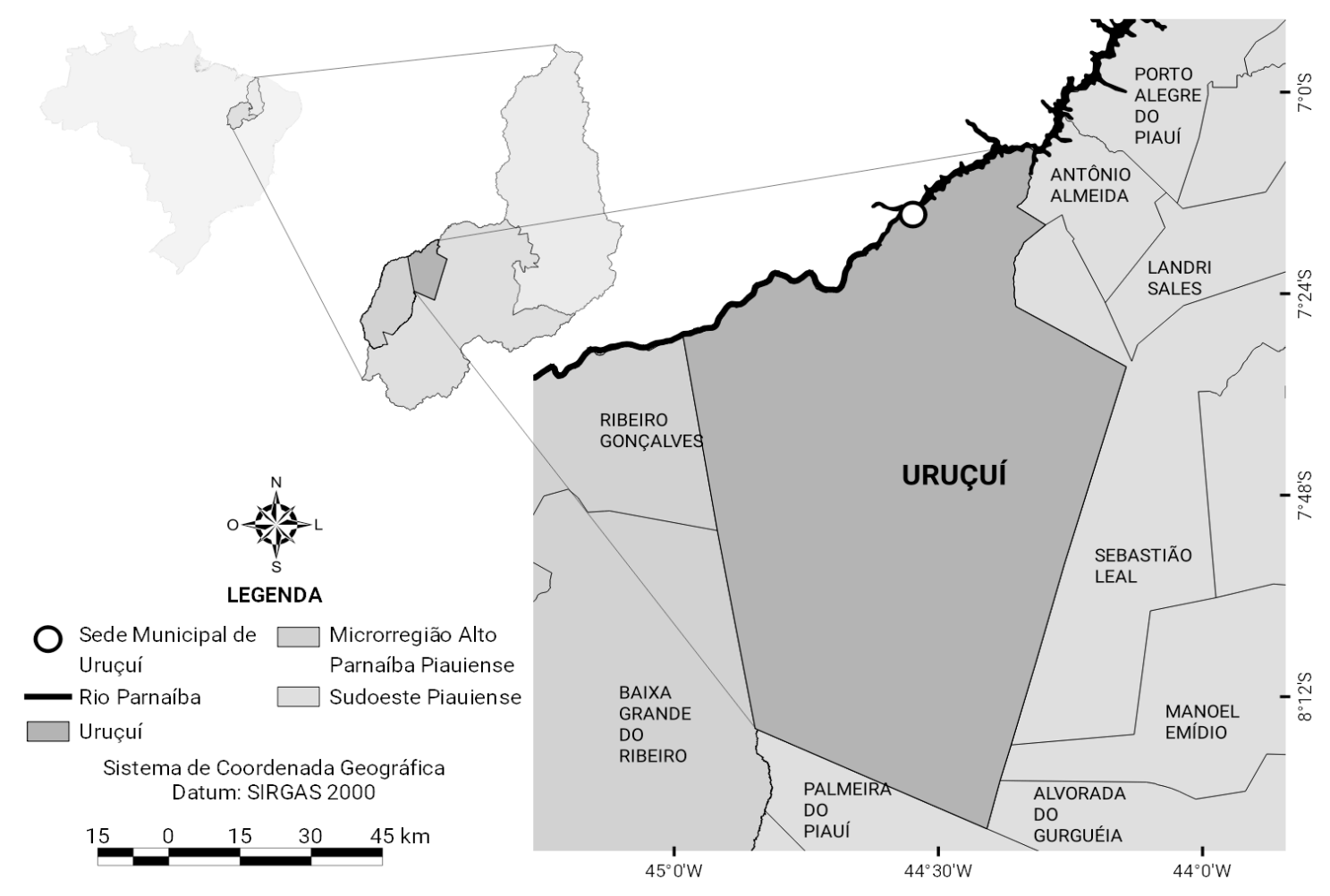

Fonte: Dantas (2017) com base em IBGE (2014)

Salienta-se, segundo Silva (2016), que em Uruçuí, a instalação do agronegócio ocorreu a partir da década de 1990, apoiadas pelas políticas públicas dos governos federal e estadual, manifestadas significamente nas aquisições de terras a preços baixos e na infraestrutura para a produção, colheita, armazenamento, beneficiamento e escoamento das safras. Também foram fundamentais para a ocupação do município, as favorabilidades climáticas, pedológicas, topográficas e hidrográficas do cerrado local, viáveis à mecanização e tecnificação; e a presença de um mercado regional atrativo. Por conta disso, constata que as transformações socioespaciais em Uruçuí, decorrentes da expansão e consolidação do agronegócio, marcaram a atividade agrícola como o elemento definidor das mudanças nas paisagens, nos padrões tecnoprodutivos e nas sociabilidades. 


\section{Classificação da pesquisa e procedimentos para a coleta e análise dos dados}

Esta investigação se embasou no método etnogeográfico, devido sintetizar as representações que a sociedade faz do espaço geográfico, como o uso dos recursos naturais, as relações de vida e os processos socioculturais (Claval, 2002). Com base no referido método, o estudo assentou-se nas análises qualiquantitativas, por circunscrever a inter-relação dos dados estatísticos e qualitativos (Kirschbaum, 2013). Logo, trata-se de uma investigação descritiva/explicativa, no qual o pesquisador ao não controlar os eventos e as variáveis, busca descrever, interpretar e avaliar a complexidade de uma realidade, de processos e/ou fenômenos (Santos, 2012).

O estudo elegeu os imóveis rurais cuja área não ultrapassasse a quatro módulos fiscais (em Uruçuí o módulo fiscal corresponde 75 hectares), por reconhecer, em conformidade com Silva (2016), que tais imóveis melhor retratam a realidade sociocultural e produtiva do agricultor familiar no cerrado piauiense. Para o cálculo de obtenção da amostra, utilizou-se o Programa Sample Size Calculator by Raosolft, por definir o erro amostral de $5 \%$ e o nível de confiança de $95 \%$, que possibilitou segurança e qualidade científica à investigação. Desse modo, do universo de 741 imóveis rurais com até quatro módulos fiscais cadastrados pelo INCRA (2013), determinou-se a amostra de 254 agricultores familiares, os quais estavam distribuídos em 17 comunidades rurais do município (Assentamentos de Flores e Santa Teresa, Graciosa, Lajeiro, Malhada da Areia, Mato Verde, Morrinhos, Pratinha, Pontes, Porto Velho, Sangue, Santo Antônio, Sucupira, Vão do Lourenço, Vereda do Mato, Tamboril e Tucuns). A seleção dessas comunidades ocorreu em virtude de acessibilidade, bem como devido os agricultores reorientarem suas estratégias econômicas e sociais de sobrevivência, embasadas na reprodução pura e simples do trabalho familiar ou como produto integrado ao agronegócio (Moraes, 2009; Silva, 2016).

As coletas foram realizadas entre os meses de fevereiro a julho de 2015, por meio de formulários e entrevistas semiestruturados, com questões guias sobre saberes, objetos e práticas de trabalho agrícola, códigos de interconhecimento, relações culturais e identidade, como também usou-se observações sistemáticas, por sugerirem "um planejamento prévio, um plano de ação e uma avaliação dos resultados" (Santos, 2012, p.209). Utilizou-se ainda gravador de áudio e diário de campo para registrar o cotidiano da pesquisa, corroborando com a necessidade de registro/descrição dos fatos com que se estava lidando.

Após a pesquisa de campo, os dados quantitativos foram tratados mediante o uso do programa eletrônico Statistical Package for the Social Sciences (Pacote Estatístico para as Ciências Sociais - SPSS). Quanto à análise qualitativa dos discursos gravados, reconheceu-se a necessidade de transcrição e leitura das falas, respeitando os depoimentos dos agricultores para possibilitar a "compreensão de como um objeto simbólico produz sentidos, como ele está investido de significados para e por sujeitos" (Orlandi, 2000, p.61).

Assinala-se que este artigo socializa parte dos resultados de pesquisa de Doutorado em Desenvolvimento e Meio Ambiente da Associação Plena em Rede das Instituições (PRODEMA) realizada na região do cerrado piauiense, a qual foi aprovada, em 2015, pelo Comitê de Ética em Pesquisa da Universidade Federal do Piauí, e registrada no Parecer Consubstanciado de Aprovação Ética, sob o número 1087335.

\section{Resultados E Discussão}

Com vista a analisar a problemática desta investigação e alcançar o objetivo geral, apresentam-se os resultados da coleta de dados realizada nas comunidades rurais de Uruçuí, sendo que da totalidade de 
trabalhadores entrevistados, 50,4\% eram do gênero masculino e 49,6\% do gênero feminino, 86\% eram casados, $6 \%$ solteiros e $8 \%$ divorciados ou viúvos. A média de idade dos pais de família era de 46 anos, enquanto das mães correspondeu a 42 anos. No tocante a estrutura familiar, estava conformada por uma média de quatro filhos. Outra característica das explorações agrícolas de Uruçuí era a presença de parcela considerável de agricultores nos postos de trabalho do agronegócio, Já que aproximadamente $62,0 \%$ possuíam algum membro da parentela com experiência de trabalho nas grandes propriedades rurais.

A respeito dos modos de vida, abordou-se nas comunidades rurais os processos socioculturais e identitários dos agricultores, descrevendo os saberes, os conhecimentos, as práticas, as tecnologias e as redes de sociabilidades. Assim, no tocante às manifestações culturais, como festividades e/ou celebrações religiosas de santos da igreja católica, identificou-se que $98,0 \%$ dos agricultores solenizavam-se às datas comemorativas do padroeiro ou da padroeira do povoado, pois historicamente o culto ao sagrado representa uma forma de solicitar a interseção (proteção) da divindade contra o profano (fenômenos sobrenaturais ou místicos), como também de agradecer pela safra atingida. Já 2,0\% das famílias não apontaram nenhuma prática cultural ligada às festividades religiosas do catolicismo, haja vista se reconhecerem como evangélicas.

De fato, ressalta-se que o respeito às leis divinas era uma particularidade inerente do agricultor familiar em Uruçuí, já que ao cultivar a terra, mantinha uma estreita ligação com a natureza, a qual, segundo a tradicionalidade camponesa, foi criada por Deus. Desse modo, descobriu-se que dos 254 trabalhadores, 59,8\% orientavam a produção agropecuária a partir de conhecimentos e experiências procedentes de princípios religiosos, mais especificamente por "votos" (pedidos) de uma safra sem perdas nem pragas; e que 40,2\% desconheciam tal contexto. Por essa razão, delineou-se que entre os comuns se reproduziam modos de vida cuja sociabilidade com a terra preservava laços de identidade com o sagrado, que se descortinava sobremaneiramente na práxis de previsão das chuvas, conforme relatou um agricultor familiar.

[...] O dia santo eu gosto de guardar, Santa Luzia, São José, São Sebastião, semana santa, eu gosto de guardar. Eu tenho essa experiência, eu guardo. Por exemplo, no dia de São José [19 de março], que é amanhã, se chover é sinal que o legume vai ser bom e ele vai ser mais apurado [produtividade]. As experiências de Santa Luzia [...] Hoje as coisas mudou (sic), muita coisa mudou, mas a gente tinha a experiência, eu mesmo botava as experiências com as pedras de sal, cinco dias antes da data de comemorar o dia da santa. Eu mesmo botava a experiência no dia de Santa Luzia, 13 de dezembro, ali você ficava [calculava], um dia daquele era um mês [o agricultor associa a quantidade de pedras de sal aos meses do calendário], aí se chovesse naquele dia era bom aquele mês, se não chover não era bom, se ficasse só emormassado [nublado] ia chover também, a gente tinha essas experiências.

Ademais, constatou-se que a interação homem/natureza nas comunidades rurais denotava costumes e linguagens potencializados na cosmovisão, na compreensão de características relativas aos aspectos ambientais do cerrado, o que contribuía para a valorização do éthos e das subjetividades culturais dos agricultores, como ficou exposto na narrativa de um agricultor familiar de 67 anos.

Olha pra saber se é um ano bom de chuva, tem a experiência do pequi [Caryocar brasiliense Cambess] e do buriti [Mauritia flexuosa L. F.]. Ano de muito pequi nós só vai (sic) ter um inverno [verão, período das chuvas] a depois que ele terminar de cair, que é mais fácil você ver um pequi seco de baixo de um pé do que ele pubo [podre] com água. O buriti vai ter a oportunidade do pequi, porque não vai ter nenhum mês que não chova duas, três chuvas, ele vai pegar aquela oportunidade daquela chuva de cair, quando depois, de novo ele torna a repetir 
a queda, até acabar o pequi o inverno chega. Se você observa isso aí, isso aí é escrito por Deus!

Essa configuração etnoecológica se coadunou com a análise de Woortmann (2009) sobre a tríade Deus/ Homem/Terra, de uma percepção da ética do equilíbrio entre a terra e os homens, na qual a pessoa dialoga com a natureza em geral e espera da mesma apenas o necessário para as demandas de consumo. Com efeito, entendeu-se que tal aspecto sociocultural incluía uma ordem moral simbolicamente marcada por princípios de reciprocidade em que os trabalhadores partilhavam a lavoura com o(a) santo(a) de devoção, com fins de assegurarem a autossubsistência do grupo, como esclareceu um agricultor de 63 anos.

Olha tem uma experiência que o camarada faz, meu pai fazia e eu aprendi. Deixava, se fosse acabar de plantar roça curta dia 13 de dezembro, deixava um pedacinho pra plantar naquele dia, aí dizia assim: esse aqui é o arroz de Santa Luzia! Meu pai fazia muito e eu faço e acredito. Dá certo!

Destaca-se que essa subjetividade cultural corroborou com a afirmação de Leff (2009), de que os padrões tecnológicos dos agricultores familiares dependem de processos simbólicos e de significação cultural que estabelecem as formas nas quais as práticas, os conhecimentos locais e os saberes tradicionais se articulam com os mitos e as crenças religiosas.

Nesse sentido, por meio da investigação identificou-se que $85,8 \%$ dos chefes de família orientavam a produção agrícola a partir de conhecimentos sobre as fases da lua, enquanto 14,2\% desprezavam esse estilo cultural de organização produtiva. Notou-se que a estreita relação com o ciclo lunar determinava o ritmo e a qualidade da lavoura. Devido a essa particularidade, os agricultores se referiam aos efeitos do cultivo sob condições geofísicas, conforme relatou um informante.

[...] lua nova é boa pra planta de rama, até ela fazer quarto-crescente a gente planta fruta de rama, como abóbora, a melancia, o feijão, essas aí. Já pras que não é de rama, depois do crescente dela até três dias depois dela ser cheia você pode plantar tudo.

Destarte, alicerçado nessa interação agricultura/ciclos ecológicos, reconheceu-se a permanência de singularidades da matriz camponesa nos modos de vida rurais em Uruçuí, pois em conformidade com as explicações de Woortmann (2009), a lua é um fundamento cognitivo que permite a leitura da natureza, posto governar a roça e, consequentemente, determinar tempos distintos para o plantio e a colheita, como também revelar uma taxonomia popular que transita entre raízes e folhagens.

E que, nas terras de trabalho, o agricultor cultivava a roça livre do controle e do rigor do cronômetro, haja vista que da totalidade da amostra, 96,0\% desenvolviam os serviços cotidianos guiados pelo Sol, enquanto 4,0\% dirigiam as tarefas diárias através do relógio, como narrou um agricultor familiar.

[...] Eu que trabalho na roça, eu vou a hora que eu quero né, mas também quando eu vou trabalhar eu entro seis horas da manhã e largo sete horas da noite, aí o dia que eu não quero ir eu não vou né. Agora, na fazenda a gente tem que ir todo dia né, bate o cartão né [...].

Salienta-se que esse panorama atestou a concepção de Santos (2009), de que o tempo social resiste aos imperativos do agronegócio, devido a instalar contra-racionalidades ao que foi instituído pelo capital.

Sendo assim, reconheceu-se que a produção agrícola familiar de Uruçuí estava fundamentada em um modo de vida que não negava a relação entre o sagrado, o místico e o natural, uma vez que o calendário agrícola se vinculava ao calendário religioso na perspectiva cosmológica em relação ao conhecimento local sobre o lugar e à experiência sobre aos ciclos lunares e as estações meteorológicas, o que refletiu a análise de Escobar (2000), de que as dimensões da cultura e do conhecimento se baseiam em processos históricos, linguísticos e culturais, os 
quais não estão dissociados das especificidades dos lugares.

Enfatiza-se, ainda, que na totalidade dos cultivos familiares, era preponderante o uso de ferramentas como enxada, machado, foice e facão, as quais eram incorporadas às diversas etapas do processo produtivo, como limpar o terreno, plantar as sementes e colher a safra. Descobriu-se que esses instrumentos se vinculavam aos chamados eco-tipos, sistemas técnicos concebidos por Wolf (1976) como resultantes de um prolongado processo de acumulação cultural, posicionando-os entre os modelos paleotécnicos (emprego de trabalho humano e animal) e neotécnicos (ancorados no uso de energia dos combustíveis fósseis e aperfeiçoamento científico), como expressa a Figura 2.

Figura 2 - Equipamentos/ferramentas empregados nas roças de Uruçuí/PI.

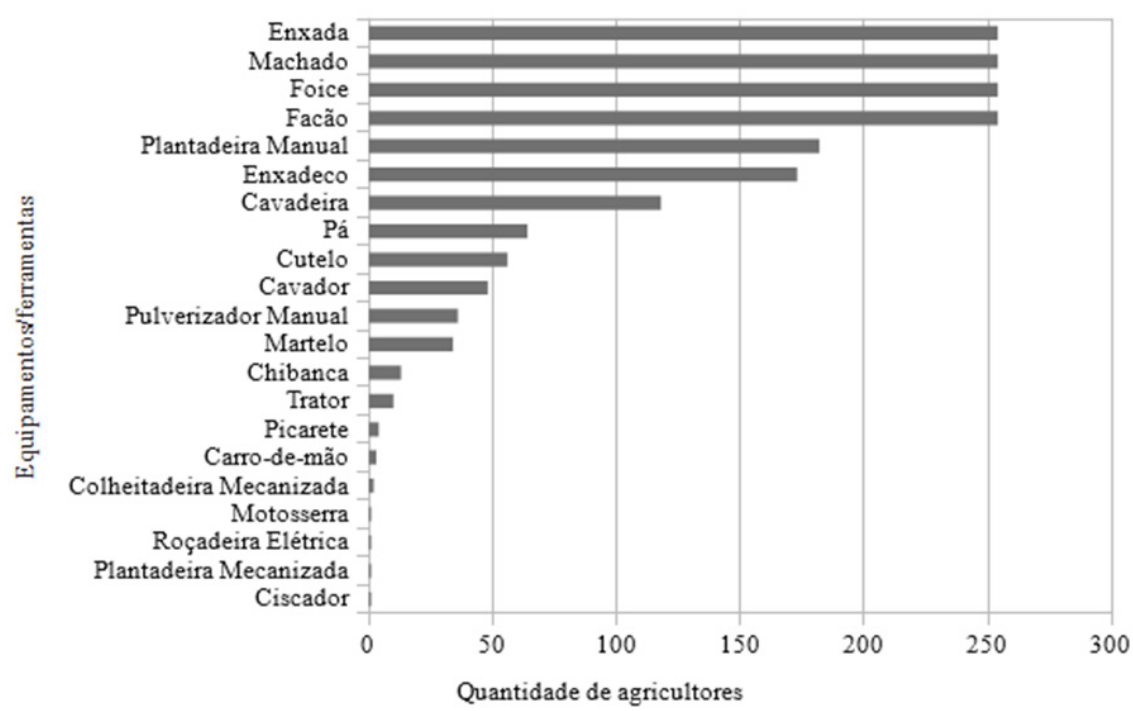

Fonte: Silva (2017)

Assim, por meio da pesquisa empírica, apurou-se a expressividade dos equipamentos e ferramentas na atividade produtiva, pois $100 \%$ dos agricultores usavam enxadas, machados, foices e facões; $71,7 \%$ plantadeiras manuais; $68,1 \%$ enxadecos; $46,5 \%$ cavadeiras; $25,2 \%$ pás; $22,0 \%$ cutelos; $18,9 \%$ cavadores; $14,2 \%$ pulverizadores manuais; $13,4 \%$ martelos; $5,1 \%$ chibancas; $3,9 \%$ tratores; $1,6 \%$ picaretes; $1,2 \%$ carros de mão; 0,8\% colheitadeira mecanizada e 0,4\%, motosserra, roçadeira elétrica e plantadeira mecanizada. Todavia, apesar deste panorama de mistura de tecnologias, registrou-se a predominância de equipamentos do chamado complexo rural, caracterizado pela lógica da produção tradicional. Patenteia-se que esse cenário foi decorrente dos baixos rendimentos monetários dos trabalhadores, uma vez que do total dos chefes de família, 46,0\% percebiam de um a menos de dois salários mínimos mensais, 33,5\% menos de um salário mínimo, 20,1\% de dois a menos de três salários mínimos e $0,4 \%$ superior a três salários mínimos. Sendo assim, reconheceu-se que essa realidade contrariou a opinião de Abramovay (2007), de que o nível de inovação e o dinamismo técnico são critérios centrais na definição de agricultura familiar, na medida em que se consubstancia como um setor ativo na economia globalizada.

Nessa perspectiva, esclarece-se que o contato dos agricultores com tratores, colheitadeiras e plantadeiras mecânicas estava condicionado a distintas circunstâncias, como aluguel e empréstimo, na medida em que da totalidade do maquinário introduzido nas roças, $69,2 \%$ era alugado, cujo valor médio da hora era $\mathrm{R} \$ 85,00$, e 30,8\% era cedido. Assinala-se que as máquinas alugadas e cedidas pertenciam a fazendas comandadas pelo 
agronegócio, próximas às comunidades.

Logo, esse quadro de inter-relações entre a produção familiar e a agricultura empresarial atestou a crítica de Lênin (1982) sobre a sobrevivência da pequena propriedade vis à vis à evolução da grande propriedade, haja vista que para não reduzir demais o rendimento da lavoura capitalista, os próprios empresários agrários e latifundiários tentam restabelecer a pequena propriedade, quando a ruína está muito avançada. Portanto, avaliou-se que a introdução do maquinário, por meio de aluguel, onerava os custos de desenvolvimento da atividade agrícola nas comunidades, uma vez que o perfil econômico denotava poucos recursos financeiros, como relatado na entrevista de um agricultor familiar.

Aqui nós tem essa dificulidade (sic), é maquinário, não tem no tempo, quando aparece já é muito tarde, esse ano mesmo fez uma seca medonha [grave] porque o inverno [estação chuvosa, inicia em novembro, às vezes em outubro, e finda em março ou abril] já começou mesmo muito tarde e aí pegou muita gente despreparado, né; eu mesmo faço minha rocinha todos os anos, eu planto pouco porque não posso pagar uma agricultura melhor, por causa do [...] é, das dificulidades (sic) que a gente tem do dinheiro, que não tem. Muitas das vezes a gente não tem o maquinário, esse ano mesmo eu limpei uma terra ali e quando foi pra dá o segundo corte pra plantar, cadê o trator?

Essa conformação ao manifestar a reduzida posse de máquinas e equipamentos modernos por parte dos produtores familiares, exprimiu as subjetividades quanto à persistência do complexo rural nos modos de vida comunitários, já que 97,6\% dos chefes de família percebiam a tecnologia utilizada nas plantações como tradicional, enquanto $2,0 \%$ a consideraram uma combinação entre o tradicional e o moderno e $0,4 \%$ a reconheceu como moderna. Embasado nesse contexto, concordou-se com Brandão (2007), no sentido de que a agricultura familiar não é marginal à evolução do capital agrário, tampouco é uma experiência social em via de eliminação, posto combinar precariamente o patrimônio cultural aos conhecimentos e às técnicas produtivas comandados pelo agronegócio, e faz isso para se favorecer da modernidade.

Acrescenta-se por meio da pesquisa empírica que dos 254 agricultores, 98,4\% adquiriram a experiência sobre as diferentes etapas do processo produtivo, por meio da transmissão transgeracional, enquanto 1, $6 \%$ através do trabalho nas grandes propriedades rurais de produção em larga escala. Esse imperativo validou as várias interpretações recorrentes na literatura científica sobre a procedência dos saberes, das práticas e dos conhecimentos desenvolvidos na agricultura familiar, como a análise de Silva (2016), que concebe a transmissão transgeracional um elemento constituinte da tradição camponesa, devido a representar a difusão de costumes e hábitos que são repassados de geração a geração, com fins de assegurar a continuidade da família, os valores culturais e a sociabilidade com a terra. Dessa forma, pontuou-se a assertiva de que os mais velhos, particularmente os pais, eram responsáveis pelo ensino dos mais jovens acerca da sistematização produtiva da lavoura, como ficou explícito no depoimento de um agricultor familiar de 63 anos.

Eu comecei a trabalhar de roça mesmo com a idade de sete anos. Eu comecei com meu pai, pois eu era ativo e tinha mesmo aquela inclinação [proximidade com a atividade agrícola]. Quando eu comecei, com dez anos em diante eu já ia pra roça sozinho, e enfrentava tudo, eu mesmo plantava, eu mesmo zelava, tinha que produzir manual porque a gente nunca tem o maquinário, né, e tem que produzir manual, ainda hoje eu faço isso.

Corroborando com esse quadro, Moraes (2009, p.144) encerra que a inserção de crianças nas práticas produtivas, em Uruçuí, iniciava-se por volta dos sete a oito anos de idade, quando desempenhavam "servicinhos maneiros", expressão generalizada entre os adultos para idealizar o primeiro contato dos filhos com a roça. 
A respeito da reciprocidade entre as famílias, percebeu-se que $99,2 \%$ dos produtores valorizavam os laços de amizade, mediante ajuda mútua, compartilhamento, redistribuição e relações de troca interfamiliar (entre os agricultores de religião católica, que durante o período da semana santa praticavam o "jejum”, que consistia no hábito de trocar alimentos na sexta-feira). Já $0,8 \%$ das famílias não materializava nenhuma forma de reciprocidade. Outrossim, notou-se que as ações de solidariedade, as quais envolviam a formação de mutirões (união de vizinhos) estavam pautadas na troca, como valor de uso, cuja totalidade se relacionava aos afazeres cotidianos, como colher a safra, cobrir casas, caçar animais silvestres, praticar a farinhada (produzir farinha e tapioca), aplicar vacinas no rebanho e efetuar a "matança" do criatório (entendida como o processo de matar, retirar o pelo ou o couro e esquartejar a carne). Assim, no conjunto da estrutura de reciprocidade local, observou-se que os esquemas tradicionais de ajuda mútua não foram dissolvidos com a chegada do agronegócio, circunstância que se harmonizou com a opinião de Sabourin (2009), de que entre as populações rurais é comum o peso das relações de proximidade e interconhecimento, consideradas essenciais para a manutenção de redistribuição familiar ou vicinal (vizinhança) da produção agropecuária.

Alicerçado no contexto apresentado, faz-se mister parafrasear Ribeiro (2012, p.75), quando acrescenta que "o mundo em que os sujeitos existem historicamente é um mundo de formas simbólicas nas quais se configura as dimensões ser-no-mundo-com-os-outros”. Assim, o agricultor familiar tem na práxis a forma por excelência de representar e organizar seu mundo, seu modo de vida.

\section{Conclusão}

Diante da análise exposta, constatou-se que o perfil cultural do agricultor familiar, em Uruçuí, denotava uma ciência do equilíbrio carregada de valores simbólicos e marcada por um patrimônio de saberes, conhecimentos, experiências e técnicas tradicionais que se ajustava precariamente às tecnologias modernas. Ademais, compreendeu-se que as relações de reciprocidade não foram diluídas com a chegada do agronegócio, tampouco a produção agropecuária desprezava as linguagens de matriz camponesa, pois articulava as práticas às significações, aos códigos socioculturais e aos fluxos de eventos externos, como fenômenos geofísicos, ciclos ecológicos e processos de regeneração da natureza; e internos, como mitos, ritos, crenças e cosmovisões.

Logo, infere-se que os modos de vida patenteiam um conceito de campesinato em processo de transformação, pois o desenvolvimento tecnológico e, consequentemente, a modernização do campo impulsionaram mudanças na natureza das relações sociais entre os sujeitos e no uso dos recursos ambientais.

Não obstante tal particularidade, entende-se que os modos de vida validam a resiliência do agricultor familiar ao processo de monopolização do patrimônio ambiental e cultural do território, que no cerrado piauiense, sobretudo, em Uruçuí, foi estrategicamente ocupado por empresas do setor agroindustrial. Com isso, percebeu-se que os agricultores familiares de Uruçuí não negavam a tradicionalidade, a qual marcava-se pela valorização da cultura e da identidade, pelas sociabilidades e pelas inter-relações agroecológicas, sendo, portanto, essencial para a reprodução das práticas produtivas, dos saberes e dos conhecimentos sobre os diversos usos do cerrado. Então, os modos de vida dos agricultores familiares do cerrado piauiense estavam ligados às formas de ver o mundo e de interpretá-lo e agir sobre ele, buscando razão para as existências e para as trajetórias de vida no espaço e no tempo.

Sublinha-se que através da interpretação dos modos de vida, pode-se (re)descobir em Uruçuí, traços 
originários da cultura camponesa que se traduzem nas virtudes do agricultor familiar nas quais incluem as atividades produtivas, a organização social, os padrões de consumo e o simbolismo. Todavia, pode-se também inferir que tais virtudes estariam em contrapontos, isto é, conectadas (encaixadas) e desconectadas (desencaixadas) ao modelo de desenvolvimento condicionado pelo agronegócio.

Ressalta-se que a análise das concepções de modos de vida do agricultor familiar, permite saber como a agricultura familiar, cuja tradição se orienta na raiz camponesa, reformula sua perspectiva econômica e sociocultural ante às novas tecnologias e racionalidades produtivas gestadas pelo agronegócio.

\section{Agradecimentos}

Agradecemos à Coordenação de Aperfeiçoamento de Pessoal de Nível Superior (CAPES) pela concessão de bolsa de estudos (nível Doutorado) para o primeiro autor, que subsidiou a realização dos estudos no cerrado piauiense.

\section{REFERÊNCIAS}

Abramovay R. 2007. Paradigmas do capitalismo agrário em questão. 3. ed. São Paulo: Edusp, 296 p.

Alves APAF. 2015. Comunidade enquanto espaço de múltiplas ações e percepções: o caso de uma comunidade quilombola em Ponta Grossa e a questão fundiária. Boletim de Geografia, 33(número especial): 43-60.

Andrade MC. 1979. O processo de ocupação do espaço regional do Nordeste. 2. ed. Recife: Sudene, pp. $37-52$.

Bourdieu P. 1988. La distinción: critério y bases sociales del gusto. Madri: Taurus, 792 p. 1991. E1 sentido práctico. Madri: Taurus, 223 p.

Brandão CR. 2007. Tempos e espaços nos mundos rurais do Brasil. Ruris, 1(1): 37-64.

FUNDAÇÃO CENTRO DE PESQUISAS ECONÔMICAS E SOCIAIS DO PIAUÍ - CEPRO. 2015. Produto Interno Bruto Municipal do Piauí 2012. Teresina: CEPRO. Disponível em: http://www.cepro. pi.gov.br/download/201502/CEPRO25 80c33d7487.pdf. Acesso em 26 de março de 2017.

Chayanov AV. 1974. La organización de la unidad económica campesina. Buenos Aires, Argentina: Ediciones Nueva Visión, 339 p.

Claval P. 2002. Campo e perspectivas da geografia cultural. In: Corrêa, R. L.; Rosendahl, Z. (Orgs.). Geografia cultural: um século (3). Rio de Janeiro: Eduerj, pp. 133-186.

Dantas F. 2017. Mapa de localização espacial de Uruçuí/PI. Teresina. 1 mapa color. Escala 1:15 km.

Deleuze G. 2001. Empirismo e subjetividade: ensaio sobre a natureza humana segundo Home. São Paulo: Edições 34, 153 p. 
Escobar A. 2000. El lugar de la naturaleza y la naturaleza del lugar. ¿globalización o postdesarrollo? In: Lander, E. La colonialidad del saber: eucocentrismo y ciencias sociales. Perspectivas latinoamericanas. Buenos Aires: Consejo Latinoamericano de Ciencias Sociales (CLACSO), pp. 68-87.

2014. Sentipensar con la tierra: nuevas lecturas sobre desarrollo, territorio y diferencia. Medellín: Ediciones Unaula, 184 p.

Feldman M e Laland KN. 1996. Gene-culture coevolutionary theory. Trends in ecology \& evolution, 11(11): 453-457.

Fernandes HR. 1992. Violência e modos de vida: “os justiceiros”. Revista Tempo Social, 4(1-2): 43-52.

Giddens A. 1991. As consequências da modernidade. São Paulo: Editora Unesp, 198 p.

Haesbaert R. 2006. Desterritorialização: entre as redes e os aglomerados de exclusão. In: Castro, I. E.; Gomes PCC, Corrêa RL. (Orgs.). Geografia: conceitos e temas. 8. ed. Rio de Janeiro: Bertrand Brasil, pp. 165-205.

INSTITUTO BRASILEIRO DE GEOGRAFIA E ESTATÍSTICA - IBGE. 2010. Censo demográfico 2010 (Piauí): características da população e dos domicílios. Resultados do universo. Rio de Janeiro: IBGE. Disponível em: http://www.ibge.gov.br/home/. Acesso em 12 de abril de 2017.

. 2014. Base cartográfica contínua, ao milionésimo (BCIM): versão 4.0. Rio de Janeiro.

. 2015. Histórico de Uruçuí. Disponível em: http://www.cidades.ibge.gov.br/xtras/perfil. php?lang=\&codmun. Acesso em 15 de abril de 2017.

INSTITUTO NACIONAL DE COLONIZAÇÃO E REFORMA AGRÁRIA - INCRA. 2013. Estrutura fundiária do Piauí por município. Teresina: INCRA (Superintendência regional do Piauí - SR 24), n/p.

Jiménez AB. 2009. La escuela rural española ante un contexto en transformación. Revista Educación, s/i(350): 449-461.

Kirschbaum C. 2013. Decisões entre pesquisas quali e quanti sob a perspectiva de mecanismos causais. Revista Brasileira de Ciências Sociais, 28(82): 179-257.

Leff E. 2009. Ecologia, capital e cultura: a territorialização da racionalidade ambiental. Petrópolis: Vozes, 440 p.

Lênin VI. 1982. O desenvolvimento do capitalismo na Rússia: o processo de formação do mercado interno para a grande indústria. São Paulo: Abril Cultural, 402 p.

Lobo ES. 1992. Caminhos da sociologia no Brasil: modos de vida e experiência. Revista Tempo Social, 4(1-2): 7-15.

Lopes JRB. 2008. Do latifúndio à empresa: unidade e diversidade do capitalismo no campo. Rio de Janeiro: Centro Edelstein de Pesquisas Sociais, 50 p. 
MacIntryre A. 1984. After virtue: a study in moral theory. Indiana: University of Notre Dame Press, 304 p.

Mendras H. 1978. Sociedades camponesas. Rio de Janeiro: Zahar Editores, 265 p.

Moraes MDC. 2003. Falas da experiência feminina: memória, narrativa e trajetória de mulheres camponesas nos cerrados piauienses. Raízes, 22(1): 30-45.

2009. Um povo do cerrado entre baixões e chapadas: modo de vida e crise ecológica de camponeses(as) nos cerrados do sudoeste piauiense. In: Godoi EP, Menezes MA, Marin RA (Orgs.). Diversidade do campesinato: expressões e categorias. v. 2 (estratégias de reprodução social). São Paulo: Unesp; Brasilia: Núcleo de Estudos Agrários e Desenvolvimento Rural, pp. 131-161.

Muñoz MG. 2003. Saber indígena e meio ambiente: experiências de aprendizagem comunitária. In: Leff E. (Coord.). A complexidade ambiental. 3. ed. São Paulo: Cortez, pp. 282-322.

Pereira FC. 2004. A sustentabilidade da agricultura familiar no vale do Gurgueia - PI: construção de novas identidades socioprofissionais. Tese (Doutorado), Programa de Pós-Graduação em Ciências Sociais, Instituto de Filosofia e Ciências Humanas, Universidade Federal do Rio Grande do Sul (UFRGS), Porto Alegre, $262 \mathrm{p}$.

Orlandi EP. 2000. Análise do discurso: princípios e procedimentos. Campinas: Pontes, 100 p.

Ribeiro EV. 2012. Reconhecimento ético e virtudes. São Paulo: Edições Loyola, 207 p.

Rigonato VD. 2014. O modo de vida das populações originárias do(s) cerrado(s) baianos. Élisée, 3(2): 62-80.

Sabourin E. 2009. Camponeses do Brasil: entre a troca mercantil e a reciprocidade. Rio de Janeiro: Garamond, $336 \mathrm{p}$.

Santos IE. 2012. Manual de métodos e técnicas de pesquisa científica. 9. ed. Niteroi: Impetus, 384 p.

Santos M. 2009. A natureza do espaço: técnica e tempo, razão e emoção. 4. ed. 5. reimp. São Paulo: Edusp, $388 \mathrm{p}$.

Scott JC. 2002. Formas cotidianas da resistência camponesa. Raízes, 21(1): 10-31.

Sepúlveda S, Rodríguez A, Echeverri R, Portilla M. 2003. El enfoque territorial de desarrollo rural. San José, Costa Rica: IICA, 180 p.

Silva AJ. 2016. Agricultura familiar e a desterritorialização/ desterritorialização/ reterritorialização provocada pelo agronegócio no cerrado piauiense: hibridismo sociocultural marginal em Uruçuí. Tese (Doutorado). Programa de Pós-Graduação em Desenvolvimento e Meio Ambiente, Universidade Federal do Piauí, Teresina, 325 p.

Silva AJ, Monteiro MSL, Barbosa EL. 2015. Difusão do agronegócio no Brasil: estratégias governamentais. Informe Econômico, 17(34): 47-54. 
2016a. Nova dinâmica produtiva e velhas questões territoriais nos cerrados setentrionais do Brasil.

Revista Espacios, 36(21): 14.

. 2016b. Contrapontos entre o tradicional e o moderno no rural. Boletim de Geografia, 34(2): 81-97.

Silva AJ, Monteiro MSL, Silva MV. 2015. Contrapontos da consolidação do agronegócio no cerrado brasileiro. Sociedade e Território, 27(3): 95-114.

Tönnies F. 1995. Comunidade e sociedade. In: Miranda, O. de. Para ler Ferdinand Tönnies. 1. ed. São Paulo: Edusp, pp. 231-352.

Wanderley MNB. 2003. Agricultura familiar e campesinato: rupturas e continuidade. Estudos Sociedade e Agricultura, s/i(21): 42-61.

Wolf ER. 1976. Sociedades camponesas. 2. ed. Rio de Janeiro: Zahar Editores, 150 p.

Woortmann EP. 2009. O saber camponês: práticas ecológicas tradicionais e inovações. In: Godoi EP, Menezes MA, Marin RA. (Orgs.). Diversidade do campesinato: expressões e categorias. v. 2 (estratégias de reprodução social). São Paulo: Unesp; Brasília: Núcleo de Estudos Agrários e Desenvolvimento Rural, pp. 119-129. 